\title{
Creative Construction Design and the Graphics Courses
}

\author{
Chao-yong Guo', Guo-yao Dong ${ }^{2}$ \\ ${ }^{1}$ Department of Vehicle and Electrical Engineering, Shijiazhuang Mechanical Engineering College,Shijiazhuang, China \\ 2 Department of Mechanical Engineering, Beijing Institute of Technology, Beijing, China \\ Guochy1963@163.com
}

\begin{abstract}
Creativeness is the necessary quality of the modem talent person. Creative construction design should be one of the core contents of the graphics courses The elements suitable to fostering creativity contained in the graphics course should be developed. The basic theory and method of the creative construction design should be used into the graphics course.
\end{abstract}

Index Terms - Creative Construction Design, Graphics Education, Graphics Course

\section{Creativeness is the Necessary Quality of the Modern Talent Person}

Creativeness is the motive force of the development of science and society. Creators should have the creative quality. The revolution in various kinds of industries, such as the revolution of information technique, electronic brain, and laser technique, is the result of creativeness. In the international market, it is necessary for the designers to have the ability to foresee and judge the needs and development of the future society, and to have the leading ideas and creative ability, if they want their products to have the advantage in the market competition. Therefore, creativeness is the requirement of the time to the talent person's quality.

The quality of creativeness is composed of various aspects, such as idea quality, thinking method quality, and knowledge accomplishment quality. Creativeness is the ability of creative thinking, is the composed part of scientific thinking. Some of the ability is innate, but more often, it comes from education and learning. So it is the task of high education to foster the creative talent person. All of the links in education chain should take fostering creative quality as the common goal. Every course plays a role of this task. But the contribution of each course is not always the same. "Creation" course is about creative science, it gives the creative theory and fosters the ability of creative thinking. The courses like "The construction of plane and solid", "Mechanism" are very suitable to foster creative thinking. The knowledge about creation can be got by studying one course, but the creative ability can be not completely fostered by one or two courses. Furthermore, all of the courses can be not suitable to fostering the creative ability. Graphics course is the suitable course to foster the creative ability.

\section{Creative Course is Suitable to Foster Creativeness}

The core and cream of the courses "Engineering Graphics Construction Design", "Engineering Design Drawing" is to foster the ability of creative thinking. They develop the function of graphics education, train and foster the thinking ability at high level. This kind of teaching content has the glamour like PC room, attracts students like magnetite, and brings student's great positive factor and interests into play. All of the scholars in graphics field agree to take construction design and design drawing as an important content of graphics. Some graphics textbooks with this content have been published recently.

For example, in multi-plane orthogonal projection, one projection drawing can't determine the shape of a solid. This uncertainty is very suitable to creative design training. Ask students to construct a solid from one projection drawing. In the procedure of construction, students should use the quality of piling up, cutting, tangent surface, intersection, real shape and so on to imitate objects or to create some shapes with special meanings. Students will not only have the training of the principle and technique of projection, but also get very wide space to create. Students can develop their intelligence, engage in the free beautiful construction, and develop their ability of creative thinking in activity.

In traditional graphics teaching, the teaching goal is to foster the ability of drawing and understanding the drawing by projection method, and the ability of thinking in terms of space images. The depth and width of the contents is determined by this goal. The elements of training creative thinking contained in the course have been ignored.

In traditional teaching, the training to figure out the third view by two given views, to supply the missed lines, to judge the correction of the third view, is mainly to foster the ability of thinking in terms of images. If we change it to the problem of construction by one view or the problem of construction with a certain volume, it will have the function of fostering the creative ability.

Let us see another example, the homework of basic exercise. In order to train the technique of using drawing equipments, and the drawing of the line types, the traditional homework is to copy an example drawing. Students do it very hard, but it is quite boring and dull. If we change this homework to the construction by given shapes, such as hexagons, circles, arrowhead shapes and so on, students will get a space to create, and they will construct beautiful and different images. It not only trains the technique of using equipments and drawing lines, but also more importantly fosters the creative ability.

Many contents in graphics course contain the creative elements and the training of developing creative thinking ability. The contents verified by practice are as following: 
- Basic construction exercise (Construction using given shapes, exercise of using drawing equipments and line types).

- Construction by the connection of arcs.

- To construct a solid from one projection drawing.

- Transformational construction with certain volume (To cut a unit cube to some pieces, and to combine them together to make a new solid).

- Construction of rotating solid (The number of axes and the relative position can be changed).

- Using the expressing method like sectional view or section to construct the components (Such as gear box, axis with gears and so on).

- Connection by thread connecting parts (To construct some components, and connect them by standard parts like bolt, stud and screw).

- Using components, such as thread, key, pin, gear, shaft, spring, roller bear, to compose parts.

- To choose different expressing method correctly and cleverly, and to express the components or assembly.

- Construction of the reasonable structure of components.

- Creative construction of assembly (Students make up it by themselves, by given function requirement or structure, by one view, or change the unsuitable structure and so on).

The items mentioned above almost cover all contents of engineering drawing. All of these come from traditional contents by changing something. It has been proved that graphics course is very suitable to foster the creativeness.

\section{Information Analogy and Image Association Creative Construction should be One of the Core Contents of Graphics Courses}

Graphics course contains the condition and elements to foster various kinds of abilities. It can foster the students' ability of drawing and understanding drawing, and the ability of thinking in terms of images according to the traditional requirement. It can also be extended to foster the creativeness. It is quite natural. If we take creativeness fostering as the teaching goal consciously, we can improve the effect of the course. It will be more suitable to the requirement of fostering modem talent person. And it will have the modern character.

Computer drawing and rough draft are the ability with modem character, but creativeness is higher level ability. One drawing can be done with traditional equipments, or with computer. No matter which way students use, they draw the projection drawing of the given structure. If they use equipments or computers to draw a structure created by themselves. they will get higher level ability.

From psychological thinking science point of view, the application and development of creative ability are most attractive. Therefore, if we lead creativeness into teaching, we can get twice the result with half the effort.

In graphics course, one aspect is to extend the creative elements. the other is to do it moderately. We can't set the standard which we can't reach it. In graphics, the creative contents are mainly the construction of geometric shapes and the nimble application of the drawing.

For example, in the construction of assembly, the structure, connection, transmission, position, seal should accord with the basic principle. The relevant geometric shapes should be found out, but it is unnecessary to have the strength and rigidity calculating and the dimension calculating. The size, dimension, tolerance, and the technology of the structure are not required to be perfect. If students can give several model schemes with engineering drawing according to the required function, the goal to foster the creativeness has been achieved, and the foundation for engineering design has been laid.

The fostering of creativeness is contained in various teaching contents and links. It is the most active content in this course. It has the modem character. So it should be one of the core contents of graphics course.

\section{The Basic Theory and Method of Graphics Construction}

As one of the core contents, it should have relevant core theory and method. In reference [5], writer gave out four basic theories of creative construction: creativity is the leading theory; projection is the basic theory; construction is the main theory; engineering science is the fundamental theory. In teaching procedure, the scientific thinking, creative method, creative quality always play the main role on learning, psychological and technique aspects. The projection is the basic theory of graphics, and it is naturally the base of constructional design. In construction, the theory of plane design, solid composition, component structure, aesthetics, are the main contents. The result of graphics creative construction should be engineering products and manufacturable. It should not be the aesthetics painting or pure art. The products should have good practicality and technology. So the engineering science is the fundament.

The textbook contains these four theories. Teachers should use them properly and gradually.

In order to operate and master this idea, it is necessary to have the relevant pattern and technique. The technique is supervised by theory, and should be combined with theory. Then it is possible to foster the talent person. The technique can be imitation, class comparing, association, translation, composition, contrast, differentiation, transformation and so on. The suitable examples should be given to help students.

The creative theory and method should run through the textbook, teaching procedure and homework, in order to achieve the goal of fostering the creative ability.

\section{Conclusions}

Creative construction design in the engineering graphics teaching is a new subject, the main purpose is to cultivate students' creativity and engineering consciousness. In the creative engineering graphics construction design teaching, it can effectively stimulate the students' ability of innovation consciousness and configuration design. Introduction of 
Creative construction design of weak links in teaching of training can also be found in time and consolidate students' mastery of knowledge points, to improve the teaching effect of engineering graphics course has a lot of help.

\section{References}

[1] Tong Bingshu and Gao Shufeng. "Cultivate students innovation ability in teaching of engineering graphics. Journal of engineering graphics, 2008 (6): pp1-6.(in Chinese)
[2] Jiang Guirong and Zhao Bingli. "Research on the innovative thinking method in engineering graphics". Teaching and research, 2005, vol28 (5): pp436-438. (in Chinese)

[3] Sun Wei, Chen Jinchang and Chen Liang. "Engineering drawing science exploration and practice in strengthening configuration creative design ability". Journal of Donghua University. 2010, vol36 (4): pp457461. (in Chinese)

[4] Wang Xiuying, Bai Haiying and Zhang Xiuzhi. "The cultivation of innovative talents of engineering graphics:The comprehensive practice" .Journal of engineering graphics, 2009 (5):pp149-152. (in Chinese) 